\title{
Measurement of craniovertebral angle with Electronic Head Posture Instrument: Criterion validity
}

\author{
Herman Mun Cheung Lau, PgD, MPhil; ${ }^{1}$ Thomas Tai Wing Chiu, PhD, MPhty St; ${ }^{1 *}$ Tai-Hing Lam, MD \\ ${ }^{1}$ Department of Rehabilitation Sciences, The Hong Kong Polytechnic University, Hong Kong, China; ${ }^{2}$ Department of \\ Community Medicine, The University of Hong Kong, Hong Kong, China
}

\begin{abstract}
This study evaluated the criterion-related validity of the Electronic Head Posture Instrument (EHPI) in measuring the craniovertebral (CV) angle by correlating the measurements of CV angle with anterior head translation (AHT) in lateral cervical radiographs. It also investigated the correlation of AHT and CV angle with the Chinese version of the Northwick Park Questionnaire (NPQ) and Numeric Pain Rating Scale (NPRS). Thirty patients with diagnosis of mechanical neck pain for at least 3 months without referred symptoms were recruited in an outpatient physiotherapy clinic. The results showed that AHT measured with X-ray correlated negatively with CV angle measured with EHPI $(r=-0.71, p<$ $0.001)$. CV angle also correlated negatively with NPQ $(r=-0.67$, $p<0.001)$ and NPRS $(r=-0.70, p<0.001)$, while AHT positively correlated with NPQ $(r=0.390, p=0.033)$ and NPRS ( $r=$ $0.49, p=0.006$ ). We found a negative correlation between CV angle measured with the EHPI and AHT measured with the X-ray lateral film as well as with NPQ and NPRS in patients with chronic mechanical neck pain. EHPI is a valid tool in clinically assessing and evaluating cervical posture of patients with chronic mechanical neck pain.
\end{abstract}

Key words: anterior head translation, cervical posture, craniovertebral angle, Electronic Head Posture Instrument, forward head posture, mechanical neck pain, neck disability, Northwick Park Questionnaire, Numeric Pain Rating Scale, postural assessment, rehabilitation.

\section{INTRODUCTION}

Neck disorders are common [1]. A review of different observational studies of neck pain around the world showed that its 1-year prevalence ranged from 16.7 to 75.1 percent for the entire adult population (aged 1770 years) with a mean of 37.2 percent [2]. A recent telephone survey in Hong Kong reported that the 1-year prevalence was 53.6 percent [3].

Proper posture maintains the musculoskeletal balance equilibrium [4], and poor posture might result in muscle imbalance that causes a faulty relationship among various body parts [5]. Forward head posture (FHP) is one of the most common cervical abnormalities that predisposes individuals toward pathological conditions, such as headache [6-7], neck pain [8-9], temporomandibular disorders [10], vertebral bodies disorders [11], soft-tissue length and strength alteration [12-13], or even scapula and shoulder dyskinesis [14-15].

Because of these associated problems, assessment of head posture has become increasingly important in clinical

\footnotetext{
Abbreviations: $\mathrm{AHT}=$ anterior head translation, $\mathrm{C} 2=$ second cervical (vertebra), C7 = seventh cervical (vertebra), CI = confidence interval, $\mathrm{CV}=$ craniovertebral, $\mathrm{EHPI}=$ Electronic Head Posture Instrument, FHP = forward head posture, HPSCI = Head Posture Spinal Curvature Instrument, ICC $=$ intraclass correlation coefficient, NPQ = Northwick Park Questionnaire, NPRS = Numeric Pain Rating Scale.

*Address all correspondence to Thomas Tai Wing Chiu, Associate Professor; Department of Rehabilitation Sciences, The Hong Kong Polytechnic University, Hung Hom, Kowloon, Hong Kong, China; 852-2766-6709; fax: 8522330-8656. Email: rstchiu@polvu.edu.hk

DOI:10.1682/JRRD.2010.01.0001
} 
practices in evaluating and designing treatment regimens for patients with neck pain and the other conditions just listed [16].

Measuring craniovertebral (CV) angle is one of the common objective methods in assessing head posture $[4,7]$. It is the angle formed by a horizontal line drawn through the spinous process of the seventh cervical (C7) vertebra and a line joining the spinous process of $\mathrm{C} 7$ vertebra with the tragus of the ear $[4,7,17]$. Other studies used lateral photographic imaging to measure CV angle [18-19]. However, it is cumbersome and inconvenient to use in clinical practices. Previous studies demonstrated that associations exist among FHP, neck pain, and disability $[4-5,9,16,20]$. The studies found that subjects with head, neck, and shoulder discomfort are more likely to have a smaller CV angle that indicates an FHP than that of asymptomatic subjects. The angle is a reliable indicator for identifying head and neck posture [4]. Fernádez-de-las-Peñas and his colleagues compared the $\mathrm{CV}$ angle of tension-type headache and migraine patients with that of nondisabled subjects. Results showed that the patient group had greater FHP, smaller CV angle [2122], and lesser neck mobility than the control group [22].

The Head Posture Spinal Curvature Instrument (HPSCI), a noninvasive and simple instrument, was designed by Wilmarth and Hilliard [17]. The HPSCI is an inexpensive method to measure CV angle. Willford et al. demonstrated that it produced consistent and stable intrarater results (intraclass correlation coefficient [ICC] = $0.9)$ across days and trials in 27 nondisabled subjects [5]. However, the accuracy of the instrument is limited to whole digits only without decimal places because no marking exists between digits.

We have developed an Electronic Head Posture Instrument (EHPI) to measure CV angle. Its measuring scale is accurate to one decimal place, and the electronic sensor reads the angle automatically. The reliability of the EHPI was assessed in our previous study, and the result showed a high intrarater (0.91-0.93) and interrater reliability (0.92-0.93) for both nondisabled subjects and those with neck pain [23]. The contrast-group comparison method was used as a first step to establish validity. However, the criterion-related validity of the EHPI, which is vital for clinical measurement, is still pending an investigation.

Cervical curvature and alignment are commonly measured and obtained from a radiograph with standard configuration [24]. Leroux and his colleagues demon- strated that a strong relationship $(r=0.84)$ and good agreement (ICC $=0.94$ ) exists when comparing the lordosis of the spine on radiological data with the skin markers on the palpable spinous process with a mean difference of $-1^{\circ}$ [25]. Therefore, we used a lateral radiograph to validate the EPHI in this study.

Anterior head translation (AHT) is the horizontal distance between the posterior superior body of the second cervical (C2) vertebra and a vertical line drawn superiorly from the posterior inferior body of the C7 vertebra (Figure 1). In cervical biomechanics, AHT is increased with FHP, forward flexion ( $x$-axis rotation), or a combination of both [26]. The amount of AHT is measured with a standard radiograph in a lateral view [27]. AHT can eliminate the soft-tissue constraint when compared with the other surface landmark measuring method [19]. This measurement method has a high intrareliability $($ ICC $=0.99-1.00)$ and interrater reliability $($ ICC $=0.99$ 1.00), with small mean absolute differences of the observer measurement [26-27]. The increased AHT will increase FHP [16]. Moreover, CV angle was found to be smaller in subjects with FHP [21-22]. Thus, this study

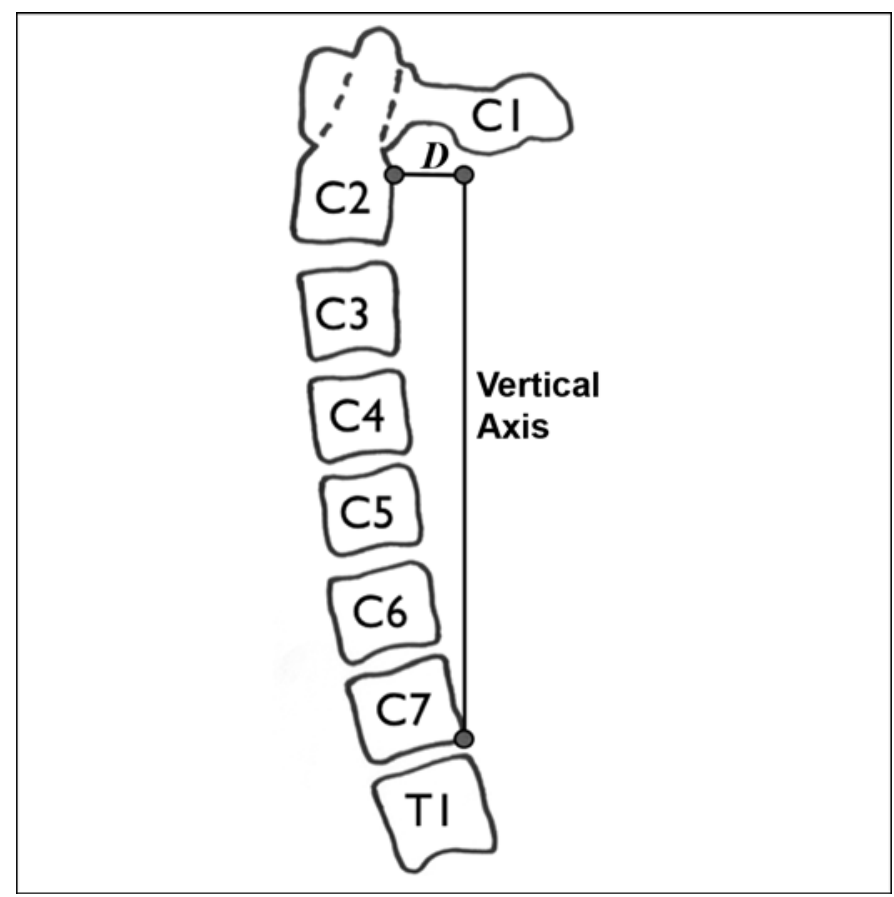

Figure 1.

Anterior head translation is measured as horizontal distance $(D)$ between posterior-superior body of C2 vertebra and vertical line drawn superiorly from posterior-inferior body of C7 vertebra. $\mathrm{T} 1=$ first thoracic (vertebra), C1-C7 = first to seventh cervical (vertebra). 
evaluated the validity of the EHPI in measuring CV angle by correlating the measurements of CV angle with AHT in lateral cervical radiographs. We hypothesize that the measurement of the EPHI accurately represents the CV angle when compared with the radiographical measurement.

\section{MATERIALS AND METHODS}

\section{Participants}

Thirty participants aged $>18$ with a diagnosis of mechanical neck pain for at least 3 months without referred symptoms were recruited from the Physiotherapy Department of the Prince of Wales Hospital, Hong Kong. Subjects were excluded if they had experienced cervical fracture or trauma, cervical surgery, idiopathic scoliosis, bone cancer, spasmodic torticollis, neurological motion disorder, any hearing impairment, temporomandibular surgery, visual impairment not corrected by glasses, or systemic disorder, such as rheumatoid arthritis or systemic lupus erythematosus. We evaluated their head postures by using both the EPHI and the traditional lateral cervical radiography. The neck pain intensity and disability were measured with the Numeric Pain Rating Scale (NPRS) [28-29] and the Chinese version of the Northwick Park Questionnaire (NPQ) [30], respectively. Explanation on the study was given, and informed consent was obtained from each subject.

\section{Procedures}

\section{Measuring CV Angle}

" $\mathrm{CV}$ angle was measured by the EHPI, which was composed of an electronic angle finder, a transparent plastic base, and a camera stand [Figure 2]. The electronic angle finder 'SmartTool,' made by M-D Building Products, was fixed on a transparent plastic base. The combined SmartTool Angle Finder and the plastic base (now named as Angle Finder) were mounted on a tripod camera or video camera stand-HAMA 'Gamma 74.' Angle Finder could be used to identify and digitally display degrees/percent slope quickly and pitch to $1 / 10$ degree accuracy. Adhesive pin markers were used to locate the position of $\mathrm{C} 7$ spinous process and the tragus of the ear.

"The EHPI was put on the standardized marking on the floor, and the tripod stand was adjusted to the position until the bubble of the horizontal indicator and the

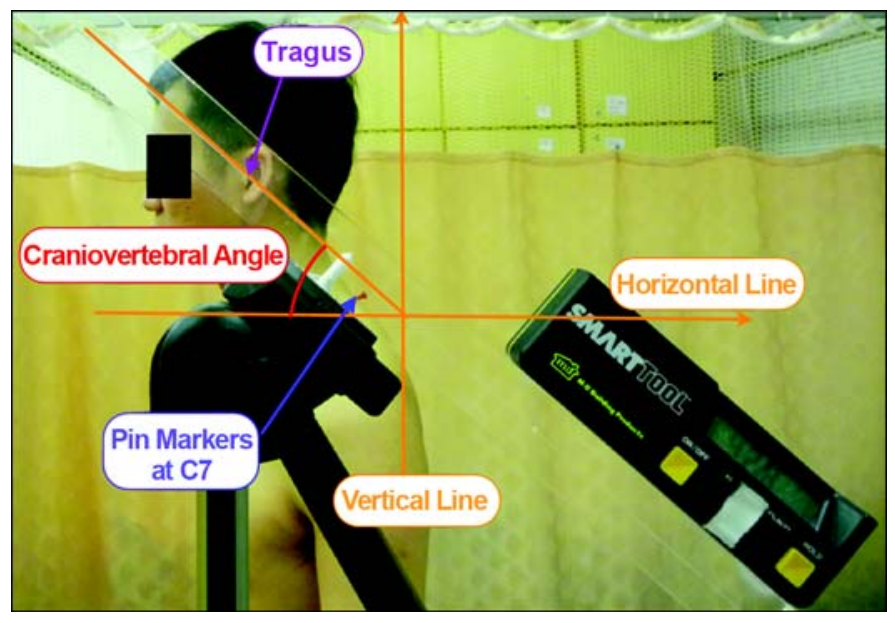

Figure 2.

Reading from SmartTool Angle Finder represents craniovertebral angle when two indicator lines were aligned with pin markers (seventh cervical [C7] vertebra spinous process) and tragus.

central marking overlapped. The distance from the participant's shoulder tip to the center of the tripod stand was standardized to $0.3 \mathrm{~m}$ while the distance between the operator's eyes and the tripod stand was $0.5 \mathrm{~m}$ because this was the longest distance that the testers could reach. The participants were asked to put on sportswear in order to expose their neck and the upper thoracic spine. They were also required to remove their socks and shoes. The C7 spinous process was palpated and identified and an adhesive pin marker [Figure 2] was attached over its midpoint of the most prominent part. The participant was then asked to stand with his/her left shoulder in front of the EPHI. Another pin marker was fixed at the tragus of his/her left ear. The participant was instructed to stand comfortably with his/her weight distribution evenly on both feet and to keep the eyes looking straight forward. $\mathrm{He} /$ she was then instructed to flex and extend the head three times and then rest it in a comfortable position. A virtual line was drawn between the two pin markers from midpoints of the tragus to C7. The therapist adjusted the EHPI until the two indicator lines were aligned with the markers. The reading from the Angle Finder represented the CV angle [as seen in Figure 2]."*

\footnotetext{
*Source: Lau HMC, Chiu TW, Lam TH. Clinical measurement of craniovertebral angle by Electronic Head Posture Instrument: A test of reliability and validity. Man Ther. 2009:14(4);363-68.
} 


\section{Measuring AHT}

Each participant had a lateral cervical X-ray taken by an experienced radiographer at the Department of Diagnostic Radiology and Organ Imaging of the Prince of Wales Hospital immediately after his or her CV angle was measured. Standardized instruction for the neutral head posture, which was used in measuring CV angle, was given to each subject for taking the $\mathrm{X}$-ray. To measure AHT on the X-ray film, two orthopedic specialists were recruited in the present study. The posterior superior body of the C2 vertebra and the posterior inferior body of the $\mathrm{C} 7$ vertebra were marked in the radiograph by an erasable marker. AHT was measured as the horizontal distance of the posterior superior body of the $\mathrm{C} 2$ vertebra to a vertical line drawn superiorly from the posterior inferior body of C7 vertebra (Figure 1).

The orthopedic specialists measured each radiograph twice at least 1 week apart. Bias was eliminated by blinding each specialist to the subjects' identification, his or her previous measurement, and the measurement of the other specialist. All evaluated radiographs were original in quality and were numbered. After measuring each radiograph, an orthopedic specialist used alcohol preparation pads to erase any markings made on the radiographs to eliminate bias for further measurement. We calculated the intrarater and interrater reliability to strengthen the validity of the study.

\section{Neck Pain Intensity and Disability}

Participants were asked to report their neck pain intensity on an 11-point NPRS, in which 0 is pain free and 10 is the most severe pain. This scale has been shown to be reliable and valid for measuring subjective pain [28-29].

Neck disability was measured with the Chinese version of NPQ that comprised nine questions. It provided a reliable and valid outcome measure for the patients with acute or chronic neck pain and demonstrated a very good content validity, a high degree of test-retest reliability, and internal consistency [30-31].

\section{Statistical Analysis}

Descriptive statistics of the age, sex, history of neck pain, CV angle, and AHT were calculated. According to Portney and Watkins, we used ICC Model 3, Form 1, to determine the intrarater reliability and Model 2, Form 2, the interrater reliability of measuring AHT [32].
To investigate the criterion validity of the EHPI, we adopted the Pearson product moment correlation coefficient to determine the degree of associations between $\mathrm{CV}$ angle as measured with EHPI and AHT as measured with $\mathrm{X}$-ray. In addition, the associations between AHT and CV angle with NPQ and NPRS were also determined by Pearson correlation. The SPSS version 15.0 program (SPSS Inc; Chicago, Illinois) was used for this statistical analysis.

\section{RESULTS}

Characteristics of the subjects are shown in Table 1. Of the 30 subjects, 53.3 percent were female (16) and 46.7 percent were male (14). The age was $46.7 \pm 9.5$, ranging from 27 to 59 years. (Values throughout article are expressed as mean \pm standard deviation, unless otherwise stipulated.) The duration of the neck pain history was $16.2 \pm 15.8$ months, ranging from 3 months to 5 years. Across the entire sample, the average $\mathrm{CV}$ angle measured was $40.8^{\circ} \pm 5.4^{\circ}$, while the mean AHT was $18.0 \pm 12.6 \mathrm{~mm}$.

The interrater reliability of the two orthopedic surgeons in measuring AHT, ICC (2,2), was 0.99 (95\% confidence interval [CI], 0.99-0.99; Cronbach $\alpha=0.99$ ). The intrarater reliability of surgeon A and surgeon B, ICC (3,1) was 0.99 (95\% CI, 0.983-0.997; Cronbach $\alpha=0.99$ ) and 0.99 (95\% CI, 0.99-0.99; Cronbach $\alpha=0.99$ ), respectively. Both the interrater and intrarater measurements had excellent reliability.

The associations between AHT from X-ray measurement and CV angle measurement of the EHPI with NPQ and NPRS are listed in Table 2. We found a moderate positive correlation of AHT with NPQ ( $r=0.39, p=$ $0.033)$ and NPRS ( $r=0.49, p=0.006)$ and a negative correlation of CV angle with NPQ $(r=-0.67, p<0.001)$

Table 1.

Subject characteristics $(N=30)$.

\begin{tabular}{ll}
\hline \multicolumn{1}{c}{ Descriptive Data } & Mean \pm SD \\
\hline Male:Female Ratio & $14: 16$ \\
Age $(\mathrm{yr})$ & $46.7 \pm 9.5$ \\
Duration of Neck Pain History (mo) & $16.2 \pm 15.8$ \\
CV Angle $\left(^{\circ}\right)$ & $40.8 \pm 5.4$ \\
AHT $(\mathrm{mm})$ & $18.0 \pm 12.6$ \\
\hline AHT - anterior head translation, CV = craniovertebral, SD = standard deviation.
\end{tabular}


Table 2.

Pearson correlation ( $r$ ) and $p$-value among anterior head translation (AHT), craniovertebral (CV) angle, Northwick Park Questionnaire (NPQ), and Numeric Pain Rating Scale (NPRS) of subjects $(N=30)$.

\begin{tabular}{|c|c|c|c|c|c|c|}
\hline \multirow{2}{*}{ Descriptive Data } & \multicolumn{2}{|c|}{ CV Angle } & \multicolumn{2}{|c|}{ NPQ } & \multicolumn{2}{|c|}{ NPRS } \\
\hline & $r$ & $p$-Value & $r$ & $p$-Value & $r$ & $p$-Value \\
\hline AHT (mm) & -0.71 & $<0.001^{*}$ & 0.39 & $0.033^{*}$ & 0.49 & $0.006^{*}$ \\
\hline CV Angle $\left(^{\circ}\right)$ & 1.000 & 0.000 & -0.67 & $<0.001^{*}$ & -0.70 & $<0.001^{*}$ \\
\hline
\end{tabular}

and NPRS $(r=-0.70, p<0.001)$. The smaller the CV angle, the greater the NPRS and NPQ values.

The association between CV angle and AHT was also explored with Pearson product moment correlation coefficient. A good negative correlation ( $r=-0.71, p<$ 0.001) was found between them, which suggested that the smaller the CV angle, the longer the AHT, and vice versa (Table 2).

As shown in Table 3, the mean CV angle and AHT for the females were $43.1^{\circ}$ and $13.3 \mathrm{~mm}$, respectively, while the males were $38.1^{\circ}$ and $23.3 \mathrm{~mm}$, respectively. Males had a smaller $\mathrm{CV}$ angle and longer AHT than those of the females. We conducted an independent-samples $t$-test to compare these parameters between males and females. We found a statistically significant difference in CV angle ( $p=$ $0.008)$ but not in AHT ( $p=0.28)$, NPRS ( $p=0.140)$, and NPQ $(p=0.086)$.

\section{DISCUSSION}

Poor head posture is generally accepted as one of the causes for neck pain because poor postural awareness and habitual poor postures may result in greater loading on the supporting structure and may cause sensitization and pain [33]. Currently, upright posture evaluation is

Table 3.

Average anterior head translation (AHT), craniovertebral (CV) angle, Northwick Park Questionnaire (NPQ), and Numeric Pain Rating Scale (NPRS) between male and female subjects.

\begin{tabular}{lcrrrr}
\hline Descriptive & \multicolumn{2}{c}{ Male } & & \multicolumn{2}{c}{ Female } \\
\cline { 2 - 3 } \cline { 5 - 6 } \multicolumn{1}{c}{ Data } & Mean & SD & & Mean & \multicolumn{1}{c}{ SD } \\
\hline AHT $(m m)$ & 23.3 & 14.2 & & 13.3 & 9.2 \\
CV Angle $\left(^{\circ}\right)$ & 38.1 & 3.9 & & 43.1 & 5.5 \\
NPQ & 39.5 & 9.6 & & 32.8 & 10.9 \\
NPRS & 4.6 & 2.0 & & 3.7 & 1.5 \\
\hline SD = standard deviation. & \multicolumn{3}{c}{} \\
\hline
\end{tabular}

recommended as part of the comprehensive physical examination of the cervical spine [34]. However, head posture is a difficult concept to capture, which is usually assessed subjectively or by complicated procedures. A clinically convenient, reliable, and valid assessment tool for head posture needs to be developed. We therefore developed the EHPI for assessing head posture and investigated the criterion-related validity of the EHPI in this study.

The intrarater/interrater reliability of AHT measurement by the two orthopedic surgeons in the present study was high and also consistent with the previous study [35]. This finding helped secure the internal validity of the present study.

The measurements from the EHPI and that of the lateral cervical X-ray of the 30 subjects with chronic mechanical neck pain were compared in this study. The result showed a moderate to good negative correlation according to the criteria suggested by Portney and Watkins [32]. That is, the smaller the CV angles, the longer the AHT distance and thus "more" FHP.

The mean CV angle in patients with mechanical neck pain was $40.8^{\circ}$, which is similar and consistent with the findings of Yip et al. [4]. The mean AHT demonstrated in the present study was $18.0 \mathrm{~mm}$, which lies within the range of 15 to $21 \mathrm{~mm}$ as revealed in the previous studies [27,35-36]. Raine and Twomey reported that an FHP is not related to an extension of the upper-cervical spine in asymptomatic women and men [18]. However, Harrison et al. suggested that anterior weight bearing of the head causes flexion of the lower cervical spine and extension of the upper-cervical spine, which increases magnitude of AHT [26]. A number of studies also recommended that subjects with FHP were more prone to neck disorder or abnormal stress over the neck structure [4,16,19-20].

The results of the present study were consistent with the findings reported by Yip et al. showing that CV angle correlated negatively with NPQ and NPRS [4]. We demonstrated that $\mathrm{CV}$ angle had a similar negative correlation with AHT as with NPQ and NPRS. The good negative 
correlation among CV angle, NPQ, and NPRS suggested that clinicians should pay special attention to patients with smaller $\mathrm{CV}$ angle because they are prone to higher pain intensity and neck disability.

No previous study has explored the association between AHT and the intensity of neck pain. The present study has demonstrated that a significant correlation $(p=$ 0.006) exists between AHT and NPRS in patients with neck pain. This finding establishes the clinical utility of AHT in assessing patients with neck pain. Moreover, it also supports use of AHT as a criterion in validating this study.

Across the sample, a significant difference was found between $\mathrm{CV}$ angle of the males and that of the females ( $p=$ $0.008)$, but not in AHT ( $p=0.28)$, NPRS ( $p=0.140)$, or NPQ ( $p=0.086)$, even though more male participants experienced anterior neck posture and had a higher disability and pain score. This sex difference was neither investigated nor shown in any previous studies. Further studies are warranted to elucidate the cause of such difference.

Validity was defined as the degree to which our test, or other measuring devices, is truly measuring what we intended it to measure [28]. We found good reverse correlation $(r=-0.72)$ between the EHPI measurement of $\mathrm{CV}$ angle and the radiological measurement of AHT. Because evaluation of head posture is recommended as an important part of the physical assessment for patients with neck or upper back pain, it may also provide an objective and reliable measurement of FHP for different therapists and medical professionals in assessing the progress of patients with neck pain. Results of the present study demonstrated that the EPHI is valid in measuring the position of head and neck. It is a simple and convenient tool in evaluating head posture.

One limitation of this study is that the sample group does not represent all types of patients with neck pain (such as acute whiplash injury) because some of the conditions were excluded. Another limitation is that the cause and effect relationship for head posture and pain and disability was not investigated in this study, which is crucial for clinicians to assess and treat their patients. Further research is warranted based on these limitations. Also, responsiveness of the EHPI, or its capability to detect change over time, should be tested in a longitudinal study for subjects with neck pain.

\section{CONCLUSIONS}

The good negative correlation between $\mathrm{CV}$ angle measured with the EPHI and AHT revealed from X-ray as demonstrated in the present study supports the recommendation that the EHPI is a valid tool in clinically assessing and evaluating cervical posture in patients with chronic mechanical neck pain.

\section{ACKNOWLEDGMENTS}

\section{Author Contributions:}

Study concept and design: H. M. C. Lau, T. T. W. Chiu, T-H. Lam. Data acquisition, analysis, and interpretation: H. M. C. Lau, T. T. W. Chiu.

Drafting of manuscript: H. M. C. Lau, T. T. W. Chiu.

Critical revision of manuscript for important intellectual content: H. M. C. Lau, T. T. W. Chiu, T-H. Lam.

Administrative, technical, or material support: H. M. C. Lau, T. T. W. Chiu.

Study supervision: H. M. C. Lau, T. T. W. Chiu.

Financial Disclosures: The authors have declared that no competing interests exist.

Funding/Support: This material was unfunded at the time of manuscript preparation.

Institutional Review: The ethics committee for the Chinese University of Hong Kong and for the Hong Kong Polytechnic University approved this study.

Participant Follow-Up: The authors do not plan to inform participants of the publication of this study because of a lack of contact information.

\section{REFERENCES}

1. Hoving JL, De Vet HC, Twisk JW, Devillé WL, Van der Windt D, Koes BW, Bouter LM. Prognostic factors for neck pain in general practice. Pain. 2004;110(3):639-45. [PMID: 15288404]

2. Fejer R, Kyvik KO, Hartvigsen J. The prevalence of neck pain in the world population: A systematic critical review of the literature. Eur Spine J. 2006;15(6):834-48.

[PMID: 15999284] DOI:10.1007/s00586-004-0864-4

3. Chiu TT, Leung AS. Neck pain in Hong Kong: A telephone survey on prevalence, consequences, and risk groups. Spine. 2006;31(16):E540-44. [PMID: 16845340]

4. Yip CH, Chiu TT, Poon AT. The relationship between head posture and severity and disability of patients with neck pain. Man Ther. 2008;13(2):148-54. [PMID: 17368075] DOI:10.1016/j.math.2006.11.002 
5. Willford CH, Kisner C, Glenn TM, Sachs L. The interaction of wearing multifocal lenses with head posture and pain. J Orthop Sports Phys Ther. 1996;23(3):194-99. [PMID: 8919398]

6. Treleaven J, Jull G, Atkinson L. Cervical musculoskeletal dysfunction in post-concussional headache. Cephalalgia. 1994; 14(4):273-79. [PMID: 7954756$]$ DOI:10.1046/j.1468-2982.1994.1404273.x

7. Watson DH, Trott PH. Cervical headache: An investigation of natural head posture and upper cervical flexor muscle performance. Cephalalgia. 1993;13(4):272-84. [PMID: 8374943] DOI:10.1046/j.1468-2982.1993.1304272.x

8. Haughie LJ, Fiebert IM, Roach KE. Relationship of forward head posture and cervical backward bending to neck pain. J Man Manip Ther. 1995;3(3):91-97.

9. Silva AG, Punt TD, Sharples P, Vilas-Boas JP, Johnson MI. Head posture and neck pain of chronic nontraumatic origin: A comparison between patients and pain-free persons. Arch Phys Med Rehabil. 2009;90(4):669-74. [PMID: 19345785] DOI:10.1016/j.apmr.2008.10.018

10. Lee WY, Okeson JP, Lindroth J. The relationship between forward head posture and temporomandibular disorders. J Orofac Pain. 1995;9(2):161-67. [PMID: 7488986]

11. Bonney RA, Corlett EN. Head posture and loading of the cervical spine. Appl Ergon. 2002;33(5):415-17.

[PMID: 12236650]

DOI:10.1016/S0003-6870(02)00036-4

12. Broer MR, Zernicke RF. Efficiency of human movement. 4th ed. Philadelphia (PA): W. B. Saunders; 1979.

13. Magee DJ. Orthopaedic physical assessment. Philadelphia (PA): W. B. Saunders; 2007.

14. Kebaetse M, McClure P, Pratt NA. Thoracic position effect on shoulder range of motion, strength, and three-dimensional scapular kinematics. Arch Phys Med Rehabil. 1999;80(8): 945-50. [PMID: 10453773] DOI:10.1016/S0003-9993(99)90088-6

15. Weon JH, Oh JS, Cynn HS, Kim YW, Kwon OY, Yi CH. Influence of forward head posture on scapular upward rotators during isometric shoulder flexion. J Bodyw Mov Ther. 2010;14(4):367-74. [PMID: 20850044]

DOI:10.1016/j.jbtm.2009.06.006

16. Griegel-Morris P, Larson K, Mueller-Klaus K, Oatis CA. Incidence of common postural abnormalities in the cervical, shoulder, and thoracic regions and their association with pain in two age groups of healthy subjects. Phys Ther. 1992;72(6):425-31. [PMID: 1589462]

17. Wilmarth MA, Hilliard TS. Measuring head posture via the craniovertebral angle. Orthop Phys Ther Pract. 2002;14: 13-15.

18. Raine S, Twomey LT. Head and shoulder posture variations in 160 asymptomatic women and men. Arch Phys Med
Rehabil. 1997;78(11):1215-23. [PMID: 9365352]

DOI:10.1016/S0003-9993(97)90335-X

19. Johnson GM. The correlation between surface measurement of head and neck posture and the anatomic position of the upper cervical vertebrae. Spine. 1998;23(8):921-27.

[PMID: 9580960] DOI:10.1097/00007632-199804150-00015

20. Szeto GP, Straker L, Raine S. A field comparison of neck and shoulder postures in symptomatic and asymptomatic office workers. Appl Ergon. 2002;33(1):75-84.

[PMID: 11831210]

DOI:10.1016/S0003-6870(01)00043-6

21. Fernádez-de-las-Peñas C, Alonso-Blanco C, Cuadrado ML, Pareja JA. Forward head posture and neck mobility in chronic tension-type headache: A blinded, controlled study. Cephalalgia. 2006;26(3):314-19. [PMID: 16472338] DOI:10.1111/j.1468-2982.2005.01042.x

22. Fernádez-de-las-Peñas C, Cuadrado ML, Pareja JA. Myofascial trigger points, neck mobility and forward head posture in unilateral migraine. Cephalalgia. 2006;26(9):1061-70. [PMID: 16919056]

DOI:10.1111/j.1468-2982.2006.01162.x

23. Cheung Lau HM, Wing Chiu TT, Lam TH. Clinical measurement of craniovertebral angle by electronic head posture instrument: A test of reliability and validity. Man Ther. 2009;14(4):363-68. [PMID: 18694655]

DOI:10.1016/j.math.2008.05.004

24. Harrison DE, Haas JW, Harrison DD, Holland B, Janik T. Sagittal skin contour of the cervical spine: Interexaminer and intraexaminer reliability of the flexicurve instrument. J Manipulative Physiol Ther. 2005;28(7):516-19. [PMID: 16182026]

DOI:10.1016/j.jmpt.2005.07.009

25. Leroux MA, Zabjek K, Simard G, Badeaux J, Coillard C, Rivard $\mathrm{CH}$. A noninvasive antrhopometric technique for measuring kyphosis and lordosis: An application for idiopathic scoliosis. Spine. 2000;25(13):1689-94.

[PMID: 10870144$]$

DOI:10.1097/00007632-200007010-00012

26. Harrison DD, Harrison SO, Croft AC, Harrison DE, Troyanovich SJ. Sitting biomechanics part I: Review of the literature. J Manipulative Physiol Ther. 1999;22(9):594-609. [PMID: 10626703]

DOI:10.1016/S0161-4754(99)70020-5

27. McAviney J, Schulz D, Bock R, Harrison DE, Holland B. Determining the relationship between cervical lordosis and neck complaint. J Manipulative Physiol Ther. 2005;28(3): 187-93. [PMID: 15855907]

DOI:10.1016/j.jmpt.2005.02.015

28. DeLoach LJ, Higgins MS, Caplan AB, Stiff JL. The visual analog scale in the immediate postoperative period: Intrasubjective variability and correlation with a numeric scale. 
Anesth Analg. 1998;86(1):102-6. [PMID: 9428860] DOI:10.1097/00000539-199801000-00020

29. Murphy DF, McDonald A, Power C, Unwin A, MacSullivan R. Measurement of pain: A comparison of the visual analogue with a nonvisual analogue scale. Clin J Pain. 1988; 3:197-99. DOI:10.1097/00002508-198712000-00003

30. Chiu TT, Lam TH, Hedley AJ. Subjective health measure used on Chinese patients with neck pain in Hong Kong. Spine. 2001;26(17):1884-89. [PMID: 11568699] DOI:10.1097/00007632-200109010-00013

31. Fielding R, Li J. A validation of the concept of current perceived health and the Current Perceived Health-42 (CPH42) questionnaire. Qual Life Res. 1997;6(1):35-42. [PMID: 9062440] DOI:10.1023/A:1026413427599

32. Portney LG, Watkins MP. Foundations of clinical research: Applications to practice. 2nd ed. Upper Saddle River (NJ): Prentice Hall; 2000.

33. Edmondston SJ, Chan HY, Ngai GC, Warren ML, Williams JM, Glennon S, Netto K. Postural neck pain: An investigation of habitual sitting posture, perception of 'good' posture and cervicothoracic kinaesthesia. Man Ther. 2007;12(4): 363-71. [PMID: 16963312] DOI:10.1016/j.math.2006.07.007

34. Janik TJ, Harrison DE, Cailliet R, Harrison DD, Normand MC, Perron DL. Validity of a computer postural analysis to estimate 3-dimensional rotations and translations of the head from three 2-dimensional digital images. J Manipula- tive Physiol Ther. 2007;30(2):124-29. [PMID: 17320733] DOI:10.1016/j.jmpt.2006.12.005

35. Harrison DE, Harrison DD, Cailliet R, Troyanovich SJ, Janik TJ, Holland B. Cobb method or Harrison posterior tangent method: Which to choose for lateral cervical radiographic analysis. Spine. 2000;25(16):2072-78.

[PMID: 10954638]

DOI:10.1097/00007632-200008150-00011

36. Harrison AL, Barry-Greb T, Wojtowicz G. Clinical measurement of head and shoulder posture variables. J Orthop Sports Phys Ther. 1996;23(6):353-61. [PMID: 8727015]

Submitted for publication January 10, 2010. Accepted in revised form June 14, 2010.

This article and any supplementary material should be cited as follows:

Lau HMC, Chiu TTW, Lam T-H. Measurement of craniovertebral angle with Electronic Head Posture Instrument: Criterion validity. J Rehabil Res Dev. 2010;47(9):911-18. DOI:10.1682/JRRD.2010.01.0001

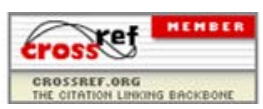

